\title{
Analysis and optimization of springback during the V-bending of hot-rolled high-strength steels (JSH440)
}

\author{
Muhammad Wasif**, Anis Fatima*, Syed Amir Iqbal*, Muhammad Tufail* and Hassan \\ Karim* \\ * Department of Industrial and Manufacturing Engineering, NED University of Engineering and Technology, Karachi. \\ ** Corresponding Author: wasif@neduet.edu.pk
}

$\begin{array}{ll}\text { Submitted } & : 03 / 07 / 2020 \\ \text { Revised } & : 10 / 05 / 2021 \\ \text { Accepted } & : 25 / 05 / 2021\end{array}$

\begin{abstract}
Influences of thickness, width, bend angle, applied load, and holding time are evaluated over the springback in hot-rolled, high-tensile strength sheet-metals (JSH-440). Blanks' thickness, width, and bend angles are considered the geometric parameters, whereas applied load and holding time are the process parameters considered in the research. Analysis of variance (ANOVA) and sensitivity analysis are applied to evaluate the significance of the factors over the springback magnitude. Analytical models are developed to predict the springback in the sheet metals for the desired geometric and process parameters. Simplified analytical models are also developed for different geometries of sheet metals. Finally, the Genetic Algorithm has also been applied to determine the optimal process parameters for the minimum springback with varying geometries of the sheet metals. Finally, the influences of parameters and optimized results are discussed in detail.
\end{abstract}

Keyword: High-tensile strength; Sheet metals; V-bending; Springback; JSH440.

\section{INTRODUCTION}

Cold or hot-rolled metal sheets with a very high length to thickness ratio are called sheet metals (Kalpakjian, 2014). Sheet metal components are formed by bending, drawing, or forming processes to generate different mechanical components, such as automotive, household, aircraft, and electronic equipment. The use of high-tensile strength sheet metals has grown in the automobile and aircraft industry, usually in reinforcement parts due to higher specific strength and good impact resistance for safety and fuel efficiency. Specific manufacturing processes are used to produce sheet metal parts, such as bending, forming, drawing, piercing, blanking, perforating, lancing, spinning, and so on.

To form the desired geometry of the final product, bending of sheet metal is the most widely used process in the industry (Kalpakjian, 2014). It is the permanent deformation of sheets, forming bends in sheet metals. Four primary sheet metal bending processes are V-bending, rotary bending, edge bending, and air bending (shown in 
Fig. 1). In the V-bending process, a set of die (female part) and punch (male part) is used to draw the sheet metal and provide bend as that in the cavity (see Fig. 1(a)).

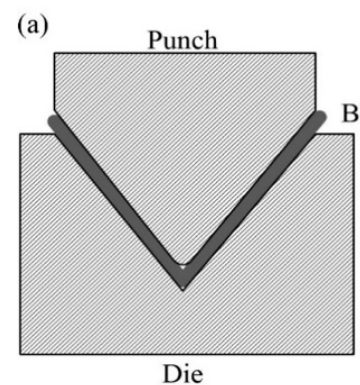

(b)

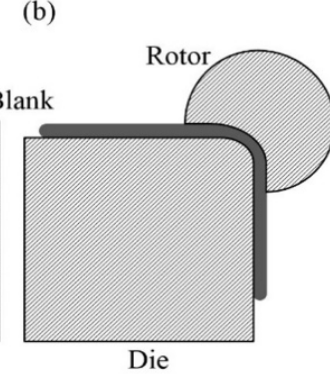

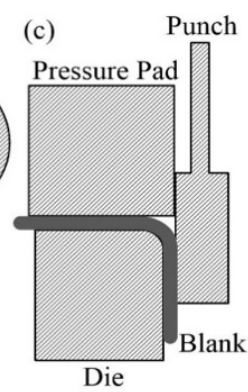

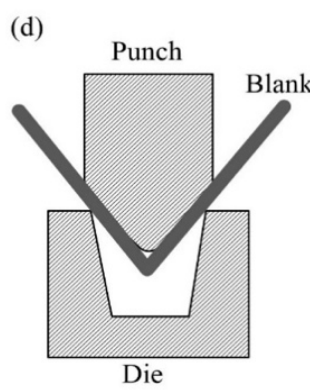

Figure 1. Bending processes for the sheet metals. (a) V-bending, (b) Rotary bending, (c) Edge bending, and (d) Air bending.

The V-bending process can produce acute, right, and obtuse angles using a die set operated in a machine tool. Pressure is gradually applied to the punch using a mechanical, hydraulic, or pneumatic press transmitted to the blank. The blank plastically bends within the cavity formed within the die set. When the pressure is removed and the punch is moved away from the blank, the blank tries to recover its shape. This elastic recovery in sheet metals due to the residual stresses is called springback and is illustrated in Fig. 2 (Lang, 1994). This elastic recovery can either be outside or inside the bend. Hence, it is recognized by negative or positive springback, which entirely depends on the sheet metal's properties and geometries (Lang, 1994).

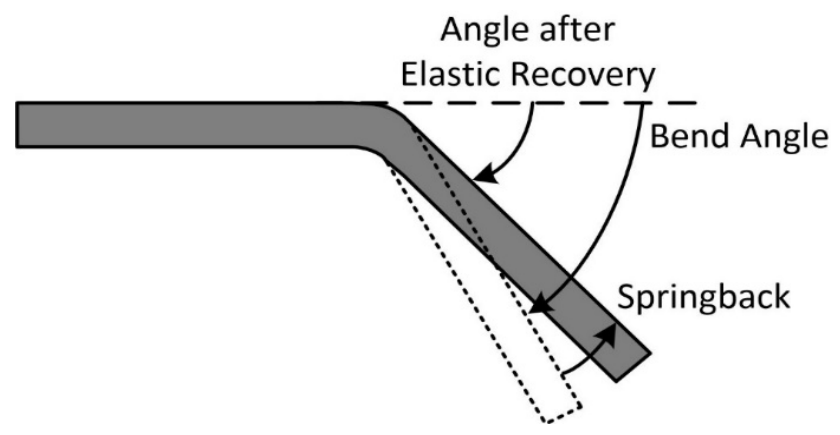

Figure 2. Illustration of springback during the bending of sheet metal.

Many parameters impact the springback in sheet metals. A few of these factors are mechanical properties, thickness, bend width, bend radius, bend angle, type of machine tool, the power source of machine tools, and tooling geometry (Kalpakjian, 2014) (Lang, 1994).

Negative springback is widely observed in high-tensile strength sheet metals, especially in Steel. In this research, this nature of springback is specially investigated with the positive springback, seldom addressed in analytical models (Kalpakjian, 2014) (Lang, 1994). Thorough literature has been reviewed to investigate the behaviour of springback in hot-rolled high-tensile strength sheet metal.

Cardena et al. (2002) reported relationships of springback with the mechanical properties of ordinary Steel and Aluminium sheet metals. Inamdar et al. (2002) developed an experimental setup for the air bending of sheet metal 
with varying mechanical properties. Using various geometries of die set and blank geometry, they studied the pattern of springback. Tekinar (2004) selected the air bending process and experimentally determined the impact of blank and modular die set geometry over the springback in Steel (nongalvanized and galvanized), Brass, Copper, and Aluminium sheet metals. Fei and Hodgson (2006) investigated the behaviour of springback in TIRP steel for the various types of sheet metal and their mechanical properties. The coefficient of friction is found to be one of the critical factors affecting the springback. Dong-juan et al. (2007) developed a mathematical model of springback depending upon Hill's yielding criterion along with the plane strain condition. Ozturk et al. (2009) used a sheet metal rolling setup for the DP steels and presented the behaviour of springback by varying rolling directions and applied temperature. Ramezani et al. (2010) used the FEM approach and related the kinetic friction with the springback during the V-bending process of ultrahigh-tensile steels. Slota and Jurcisin present another springback prediction model for the TRIP, AHSS, and mild Steel during the air-bending process (Slota and Jurcisin, 2012). A comparative analysis for the springback is presented in Da Silva et al. This research differentiates the behaviour in springback in advanced high-tensile strength material sheet-metals (DP600 and DP780) during the air-bending process (Da Silva et al., 2016). Leu and Zhuang (2016) used the finite element modelling technique to develop a springback model in high-strength sheet metals (cold-rolled SPFC 440 and SPFC 590) to optimize the blank thickness, mechanical properties of the material, and die-set geometry. Yang et al. (2016) performed experimental analysis on springback in advanced high-strength steel (DP780) by varying process parameters during the airbending process. They also used the experimental data to develop an analytical model to predict springback in these metals. Jung et al. (2017) presented a springback prediction model for the U-bending of dual phased-steels using the experimental data. Ramadass et al. (2018) minimized the springback in Titanium grade steel sheets, using the finite element modelling and experimental technique by optimizing blank, die set geometry, and the process parameters. Choi et al. (2018) used FEM modelling and experimental validation of springback for the single and double stage U-bending in TWIP 980 sheet metals.

Nakagawa et al. (2018) analysed the effect of quenching, after the sheet metal stamping process, over the springback in ultra-high-strength Steel thin sheets with a tensile strength of $1.5 \mathrm{GPa}$. Noma et al. (2018) developed a unique strength differential model (SDM) based on the FEM technique for the springback in very high-tensile strength sheet metals (tensile strength more than $980 \mathrm{MPa}$ ). This model can predict the springback in sheet metals for different mechanical properties and blank geometries. Liu et al. (2019a, 2019b) developed FEM models and analysed the springback in different geometries of reinforcement members. They studied the effect of springback during the milling process over the titanium square tubes. Experimental results show that springback is directly proportional to the radius of bent tubes. Cai et al. (2019) studied the behaviour of springback by increasing temperature during the U-bending process over the high-strength aluminium alloy (AA6082). Lin et al. (2019) developed a springback FEM model for the bending of U-Channels of MP980 and AA6022-T4. They concluded that the yield criteria are an essential parameter for improved accuracy of springback prediction in FEM models. Ren et al. (2019) presented an in-progress springback compensation technique for the sheet metal part with arbitrary geometry having a tensile strength of $68 \mathrm{GPa}$. Balon et al. (2019) performed FEM analysis for the springback during the cold and hot forming on the specific geometry of blanks of HCT 780X steel. They concluded that higher springback is observed during the cold forming of sheet metals. Pornputsiri and Kanlayasiri (2019) performed an analysis of springback concerning change in the microstructure of Transformation Induced Plastic Sheets (TRIP) by adopting real-time heat controlling techniques. In another research, Leu et al. (2019) presented a mathematical model relating mechanical properties of SPFC 440 (cold-rolled) with the limited geometric parameters of the sheet metal blank and elastic recovery during the V-bending process. Wasif et al. (2020) presented research consisting of springback analysis during the V-bending in high-strength steels (JSC440 and JSC590) along with the analytical model and optimization results. Cui et al. (2020) presented a unique experimental analysis, where magnetic flux has been applied during the bending, which provided promising results. Umur et al. (2020) performed an experimental investigation of springback in DP600 and DP780 sheet metals by varying thickness, die curvature, and punch tip radius. 
The literature cited above shows the effects of springback on several types of sheet metals. Several models are reported in the earlier research relating the geometry of blank, die set, and process parameters with the springback. These models are specific to the materials and depend on the composition of sheet metals. It is observed from the extensive literature review that in each of the research, two to three process parameters have been analysed for the specific types of sheet metals. In continuation with the previous research, an extended analysis of springback due to bend angle, thickness and width of the sheet, applied press load, and holding is performed over the hot-rolled hightensile strength steels (JSH440). V-bending of different angles has been applied over the blanks of JSH440 with varying widths and thicknesses. Machine tools parameters, applied load, and holding time are also considered to study their influence over the springback. An analytical model for the springback is also presented, which relates blank geometry and machine tool parameters to the springback. Optimization of these parameters is performed to minimize the springback. At the same time, the influence of these parameters over the springback is discussed in detail. The research clearly shows that the negative springback exists in hot-rolled high-tensile strength steel, which cannot be predicted with the generic analytical models. These depend on the materials' mechanical properties and do not incorporate the compressive behaviour during the springback (Wasif et al., 2020). Furthermore, the analytical models of springback presented in this research can predict the springback in JSH440 with the five process parameters.

\section{METHODOLOGY}

Hot-rolled high-tensile strength steel is widely used in the automobile and machine tool industry due to its extensive properties and availability. The industry's' main requirement is to predict the springback in high-tensile strength material for the different settings of process, tool, and blank geometry parameters and optimize those for the minimum springback. Hence, in this research, experimental investigation has been performed to analyse springback behaviour in hot-rolled high-strength sheet metals (JSH440), to facilitate the industry with optimized outcomes of springback. According to the material composition of JSH440, it contains the following elements by weight for maximum of $2 \%$ Manganese $(\mathrm{Mn}), 0.1 \%$ Columbium $(\mathrm{Nb}), 0.25 \%$ Carbon $(\mathrm{C}), 0.1 \%$ Titanium (Ti), $0.03 \%$ Sulphur (S), $0.6 \%$ Silicon (Si) , 0.05\% Phosphorus (P), 0.1\% Boron (B), $0.1 \%$ Aluminium (Al), and rest of $96.67 \%$ of Ferrous (Fe) (JFE Steel Corp, 2019).

Experiments are designed to analyse the impact of blank geometry and bending parameters over the springback in JSH440 steel. A hydraulic press of load up to 75 tons has been selected to perform the v-bending of JSH440 sheet metal. Three sets of bending punch and die, made of medium carbon steel, have been developed to bend sheet metal strip to angles of $60^{\circ}, 90^{\circ}$, and $120^{\circ}$. A digital bevel gauge is used to measure the bend angles of metal strips. Design of experiment (DOE) has been employed to setup up different combinations of process parameters for the V-bending of JSH440. Process parameters related to the blank geometries are bend angle, the width of strip, and thickness of the strip, whereas process parameters related to machine tools are applied load and blank holding time between the die and the punch. Each experiment is repeated thrice in random manner to eliminate the biasness in the data gathering. Measurements of bend angles through the digital bevel gauge have been collected through the experimental results, investigating the effects of varying process parameters over the springback. Analysis of Variance (ANOVA) is applied over the experimental results to determine the most influential parameters affecting the springback in JSH440. Results of springback are plotted against each process parameter to investigate the trend of outcome with respect to the varying process parameters. Mathematical models have been established using the experimental data to predict springback during the V-bending of JSH440 sheet metals, with different combinations of the parameters. Finally, optimal bending parameters for different geometry of blanks are presented with minimum springback in JSH440 during the V-bending process. 


\section{EXPERIMENTAL SETUP}

The experiments' factorial design is applied to analyse the effects of blank geometry and machine tool parameters over the springback during the V-bending of hot-rolled high-tensile strength steel (JSH440). Five essential controllable parameters, including blank geometry and machine tools parameters, have been selected to study the springback behaviour to limit the number of experiments in the research. A 75-ton hydraulic press with varying applied load of $30 \mathrm{kgcm}^{-2}$ and $180 \mathrm{kgcm}^{-2}$ is selected. Table 1 presents the process parameter along with the varying levels. Table 2 illustrates the controllable parameters kept unvaried.

Each bend is replicated to avoid human error, and the average value of two bend angles is taken as the final springback. The sequence of bending is selected randomly to avoid the biases of results. It is also to be noted that the source of the sheet metal strips is single and standardized. Hence, there is no need for blocking during the design of experiments. Sheet metal blanks are bent up to the defined angles using the hydraulic press, which angles are measured using a digital bevel protector. Forty-eight experiments with varying parameters 6 are designed, which are replicated once. Hence, a total of 96 strips are bent. Measured springback data is gathered and statistically analysed using the Minitab Educational Version (Minitab, 2019).

Table 1. Blank Geometry and Machine Tool Parameters.

\begin{tabular}{|c|c|c|c|c|c|}
\hline \multirow{2}{*}{ S. No. } & \multirow{2}{*}{ Parameter } & \multirow{2}{*}{ Type } & \multicolumn{3}{|c|}{ Levels } \\
\hline & & & I & II & III \\
\hline 1. & Thickness - T (mm) & \multirow{3}{*}{ Blank Geometry } & $\mathrm{T} 1=1.4$ & $\mathrm{~T} 2=1.6$ & -- \\
\hline 2. & Width - W (mm) & & $\mathrm{W} 1=20$ & $\mathrm{~W} 2=50$ & -- \\
\hline 3. & Bend Angle - A (degree) & & $\mathrm{A} 1=60$ & $\mathrm{~A} 2=90$ & $\mathrm{~A} 3=120$ \\
\hline 4. & Load - L $\left(\mathrm{kgcm}^{-2}\right)$ & \multirow{2}{*}{$\begin{array}{l}\text { Machine Tool } \\
\text { Parameter }\end{array}$} & $\mathrm{L} 1=30$ & $\mathrm{~L} 2=180$ & -- \\
\hline 5. & Holding Time - H (sec) & & $\mathrm{H} 1=0$ & $\mathrm{H} 2=10$ & -- \\
\hline
\end{tabular}

Table 2. Parameters kept constant.

\begin{tabular}{|c|c|}
\hline Parameters & Value \\
\hline Length of blank & $170 \mathrm{~mm}$ \\
\hline Inner bend radius or radius of the punch & $8 \mathrm{~mm}$ \\
\hline Outer bend radius or radius of the die & $10 \mathrm{~mm}$ \\
\hline
\end{tabular}

The main hypothesis of the research assumes that the controllable factors identified in Table 1 and their interactions do not influence the springback, and hence the mean springback achieved by varying the parameter levels remains the same. Alternate hypothesis assumes vice versa. That is, varying levels of the parameters or their interactions affect the mean springback. Hence, Analysis of Variance (ANOVA) will be applied to the data of springback to assess the trueness of the hypothesis. 


\section{ANALYSIS OF SPRINGBACK}

ANOVA depicts the significance of the influence of controllable parameters over the response variable. Table 3 shows the ANOVA applied to the springback data gathered through the measurement. In Table 3, the P-value for the specific F-value less than 5\% depicts that the probability of occurrence of the main hypothesis for the controllable factors or their interactions does not lie within $95 \%$ confidence interval. Hence, alternate hypothesis is true, and the factors or their interactions do not significantly influence the springback. In the case of P-value being higher than $5 \%$ depicts that the main hypothesis is true, and the factors or their interaction do not significantly influence the springback.

ANOVA presented in Table 3 suggests that the blank geometry parameters, thickness, width, and bend angle are the significant factors that influence the springback since their P-values are less than $5 \%(0.05)$. At the same time, load and holding time do not significantly influence the springback having P-values higher than 0.05 . It can also be seen from the same table that the interactions of the factors also insignificantly influence the springback. From Table 3, the highest influencing factor over the springback is thickness having the highest F-value of 62.44. Bend angle and thickness are the other factors influencing springback with F-values of 55.9 and 15.31, respectively. To further investigate the behaviour of springback, springback data gathered through the measurements are plotted against each of the process parameters (shown from Fig. 3 to Fig. 7). Each curve presented below shows the variation in springback due to the change in a single process parameter, keeping the other parameters constant. Variation in Springback during the V-bending of JSH440 due to different sheet thicknesses is shown in Fig.3. Here, each curve represents a sample bent using a specific set of process parameters. The black solid curve with a black circle marker is marked as S1 (see legends in Fig. 3). This curve represents the variation in springback due to the change of thickness from $1.4 \mathrm{~mm}$ to $1.6 \mathrm{~mm}$ while keeping constant parameters, which are press load to level 1 (L1), holding time to level 1 (H1), bend angle to level 1 (A1), and width of the strip to level 1 (W1).

Table 3. ANOVA for the Springback in JSH440 Sheet Metals.

\begin{tabular}{|l|c|c|c|c|c|}
\hline Source & DOF & Adj. SS & Adj. MS & F-Value & P-Value \\
\hline Thickness (mm) & 1 & 60.767 & 60.7669 & 62.44 & 0.000 \\
\hline Width (mm) & 1 & 14.899 & 14.8992 & 15.31 & 0.000 \\
\hline Bend Angle (Degree) & 1 & 54.403 & 54.4032 & 55.90 & 0.000 \\
\hline Load & 1 & 2.086 & 2.0865 & 2.14 & 0.153 \\
\hline Holding Time & 1 & 0.211 & 0.2112 & 0.22 & 0.645 \\
\hline Bend Angle (Degree)*Bend Angle (Degree) & 1 & 3.757 & 3.7567 & 3.86 & 0.058 \\
\hline Thickness (mm)*Width (mm) & 1 & 0.178 & 0.1781 & 0.18 & 0.672 \\
\hline Thickness (mm)*Bend Angle (Degree) & 1 & 0.325 & 0.3248 & 0.33 & 0.568 \\
\hline Thickness (mm)*Load & 1 & 0.455 & 0.4552 & 0.47 & 0.499 \\
\hline Thickness (mm)*Holding Time & 1 & 0.036 & 0.0361 & 0.04 & 0.849 \\
\hline Width (mm)*Bend Angle (Degree) & 1 & 0.870 & 0.8698 & 0.89 & 0.352 \\
\hline Width (mm)*Load & 1 & 1.473 & 1.4732 & 1.51 & 0.228 \\
\hline Width (mm)*Holding Time & 1 & 0.222 & 0.2224 & 0.23 & 0.636 \\
\hline
\end{tabular}




\begin{tabular}{|l|c|c|c|c|c|}
\hline Bend Angle (Degree)*Load & 1 & 1.166 & 1.1663 & 1.20 & 0.282 \\
\hline Bend Angle (Degree)*Holding Time & 1 & 1.226 & 1.2261 & 1.26 & 0.270 \\
\hline Load*Holding Time & 1 & 0.069 & 0.0687 & 0.07 & 0.792 \\
\hline Error & 31 & 30.171 & 0.9732 & & \\
\hline Total & 47 & 172.315 & & & \\
\hline
\end{tabular}

Fig. 3 shows the variation in springback due to a change in JSH440 sheet thickness. Fig 3(a) shows that both positive springback and negative springback exist in JSH440 sheet metal strips, which vary with the change in thicknesses. Upward trends in curves above the zero springback show the increase in the magnitude of springback, where the upward trend in the curve below the zero springback value mentions the decreasing magnitude of springback (refer to Fig. 3(a)). The highest magnitude of springback, 3.75 degrees, is observed in the strips having thickness of 1.4mm and bent with parameters levels L1, H1, A2, W2 (S4) and L2, H1, A2, W2 (S16). Here, it is common in both blanks that the holding time is zero, whereas, bent angle and width of the strips are $90^{\circ}$ and $50 \mathrm{~mm}$, respectively. Springback in these strips is drastically reduced and reached up to a negative springback of -1 degree. The least springback is observed in curve S7, having the most negligible load, angle, and width but having a holding time of 10 seconds. From Fig. 3, negative springback is highly occurred in the blanks having obtuse bent angle $\left(\mathrm{A} 3=120^{\circ}\right)$ in curves S5, S6, S11, S17, S18, S23, and S24. The compressive residual stresses in the obtusely bent blanks dominated over the tensile one and caused the negative springback in the strips. Compared to moderate and low tensile strength materials, this phenomenon is only observed in high-tensile material, which is also evident in earlier research where cold-rolled high-tensile strength materials were used (Wasif et al., 2020). Despite the random occurrence of negative springback, it has been observed only in the blanks bent to $120^{\circ}$.

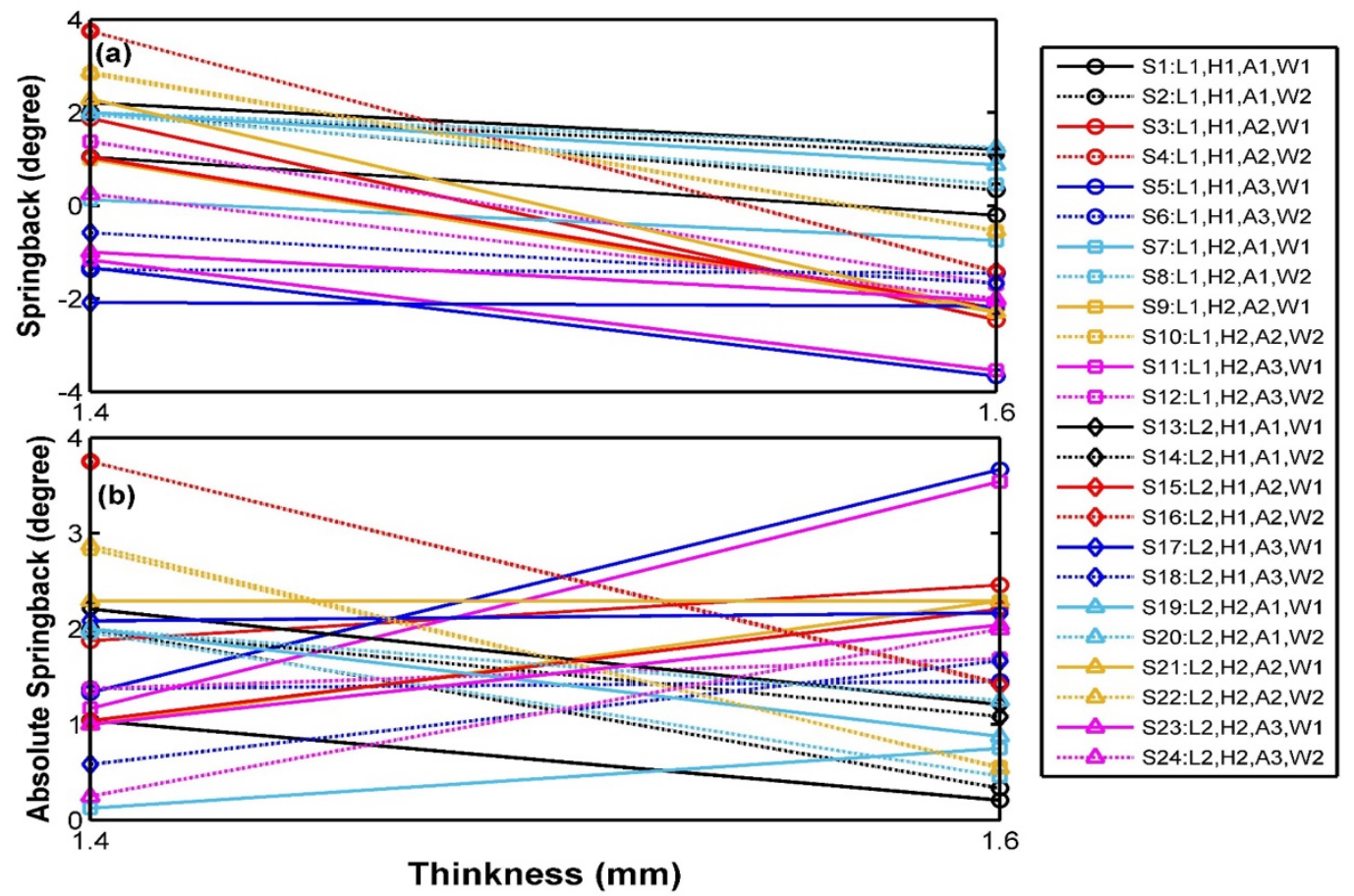

Figure 3. Variation in springback due to change in sheet metal thickness: (a) thickness versus springback, (b) thickness versus absolute springback. 
Fig. 3(b) is drawn to present the absolute springback in the strips. Springback increases with the thickness, especially in the strips bent to $120^{\circ}$. High springback magnitudes are observed in the blanks bent to $120^{\circ}$, with the load of $30 \mathrm{kgcm}^{-2}$, having a width of $20 \mathrm{~mm}$ (curves S5 and S11). A slight increase in springback occurred when the strips are bent with the higher load of $180 \mathrm{kgcm}^{-2}$. It is due to the applied load, which overcomes the residual stresses stored in the strips and prevents elastically deform. Form Fig. 3(b), in most dotted curves (having a width of 50mm), springback magnitude reduces with the thickness. An exception to this behaviour only exists in the strips bent to the angle of $120^{\circ}$ (curves S18 and S24). Springback magnitude usually increases as the thickness is increased, in most of the strips having a thickness of $20 \mathrm{~mm}$ (all solid colour curve). An exception has been observed in the curves S1, S13, and S19, where strips are bent to an angle of $60^{\circ}$. It may be due to the geometry of the strip bent to an acute angle, where compressive and tensile residual stresses within the bent are pretty low and balanced.

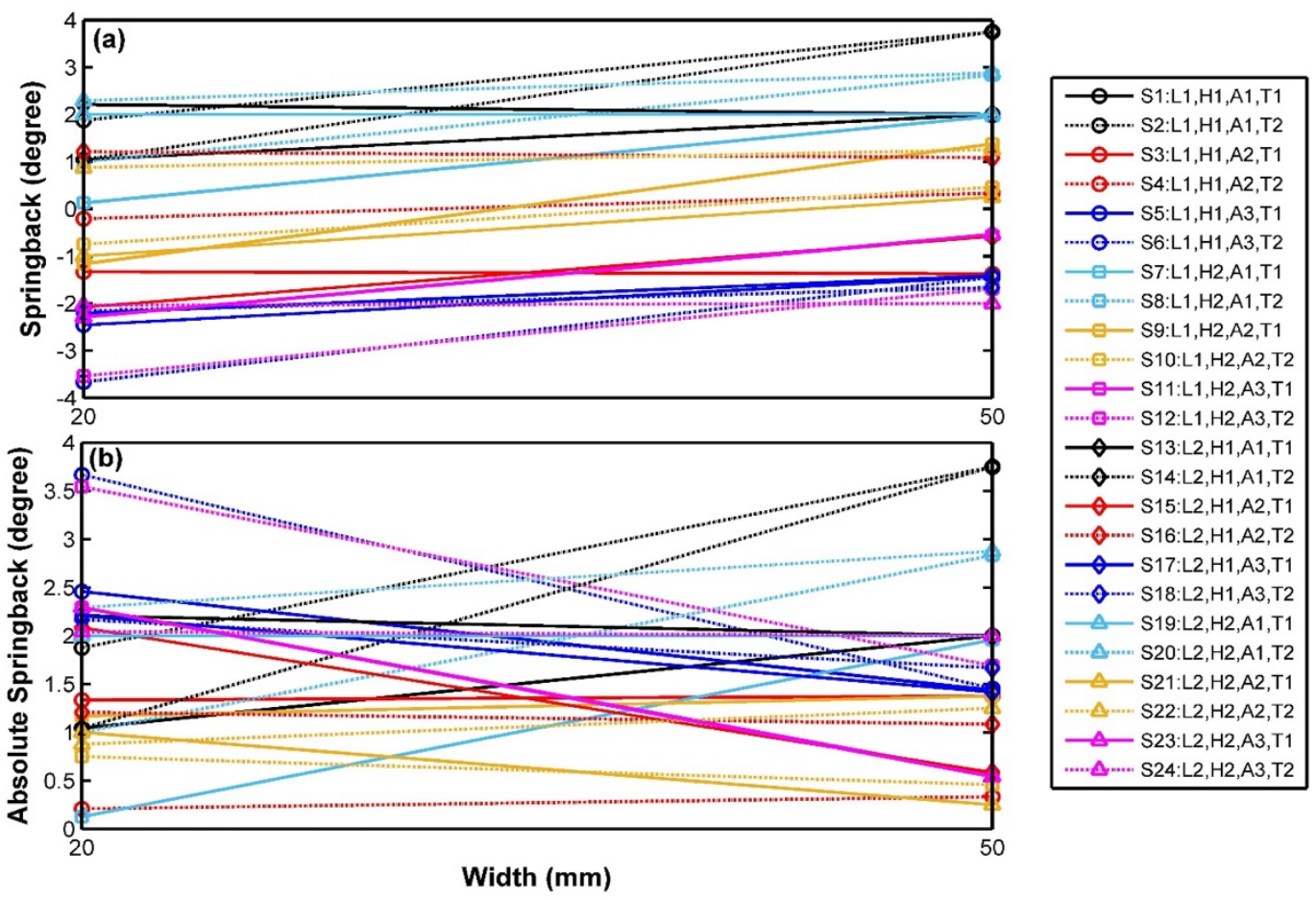

Figure 4. Variation in springback due to change in sheet metal width: (a) width versus springback, (b) width versus absolute springback.

Fig. 4 presents the influence of JSH440 strip widths over the springback. Fig. 4(a) shows that the strips bent to the angle of $60^{\circ}$ possess positive springback, which generally increases with the width. The springback increase with the width, if it is bent to an acute angle, it is due to the large area around the bend of the strip storing more considerable tensile residual stresses, causing the positive springback. Negligible springback with the increase of width is observed in curves S3, S16, and S22. This springback is observed in the blanks bent to $90^{\circ}$, even with the load of $180 \mathrm{~kg} \mathrm{~cm}^{-2}$. Contrary to this situation, negative springback occurred in most of the strips that bent to $90^{\circ}$ and $120^{\circ}$ as shown in Fig. 4(a) in curves S4-S6, S9-S12, S15-S18, and S21-S24. Fig 4(b) shows that negative springback in the strips reduces with the width bent to either $90^{\circ}$ or $120^{\circ}$. Maximum springback occurred in the strips bent to an angle of $120^{\circ}$, having the width of $20 \mathrm{~mm}$ with the thickness of $1.6 \mathrm{~mm}$ (see curves S6 and S12) and in the strips bent to $60^{\circ}$, having the width of $50 \mathrm{~mm}$ with the thickness of $1.6 \mathrm{~mm}$ (see curves S2 and S14). 
Fig. 5(a) shows positive springback in most of the strips bent at $60^{\circ}$. On the contrary, curves S3 and S7 show negative springback having a thickness of $1.6 \mathrm{~mm}$. Fig. 5(a) also shows that the positive springback generally occurs in the sheet metal strips having a thickness of $1.4 \mathrm{~mm}$ (all the blue and black curves) bent within the acute angles. Negative springback occurred in few of these strips while bent to $120^{\circ}$ (see curves S1, S5, S9, and S13 in Fig. 5(a)). Negative springback is seen in the strips bent to $120^{\circ}$ having a thickness of $1.4 \mathrm{~mm}$ due to the higher tensile residual stresses in the lower thickness bent. Fig. 5(a) also shows that negative springback generally exists in the strips having thicknesses of $1.6 \mathrm{~mm}$ bent to $90^{\circ}$ and $120^{\circ}$. It usually occurred in the strips (except S8 and S16) due to the bending at right and obtuse angles, causing dominant tensile residual stresses within the bend resulting in negative springback. Fig. 5(a) shows that the highest positive springback is observed in the strips bent to $90^{\circ}$ having the thickness of $1.4 \mathrm{~mm}$ and width of $20 \mathrm{~mm}$, whereas the highest negative springback is observed in the strips bent to $90^{\circ}$ having a thickness of $1.6 \mathrm{~mm}$ with the same width. Hence, springback nature shifts from positive to negative as the bent angle is increased from acute to obtuse angles.

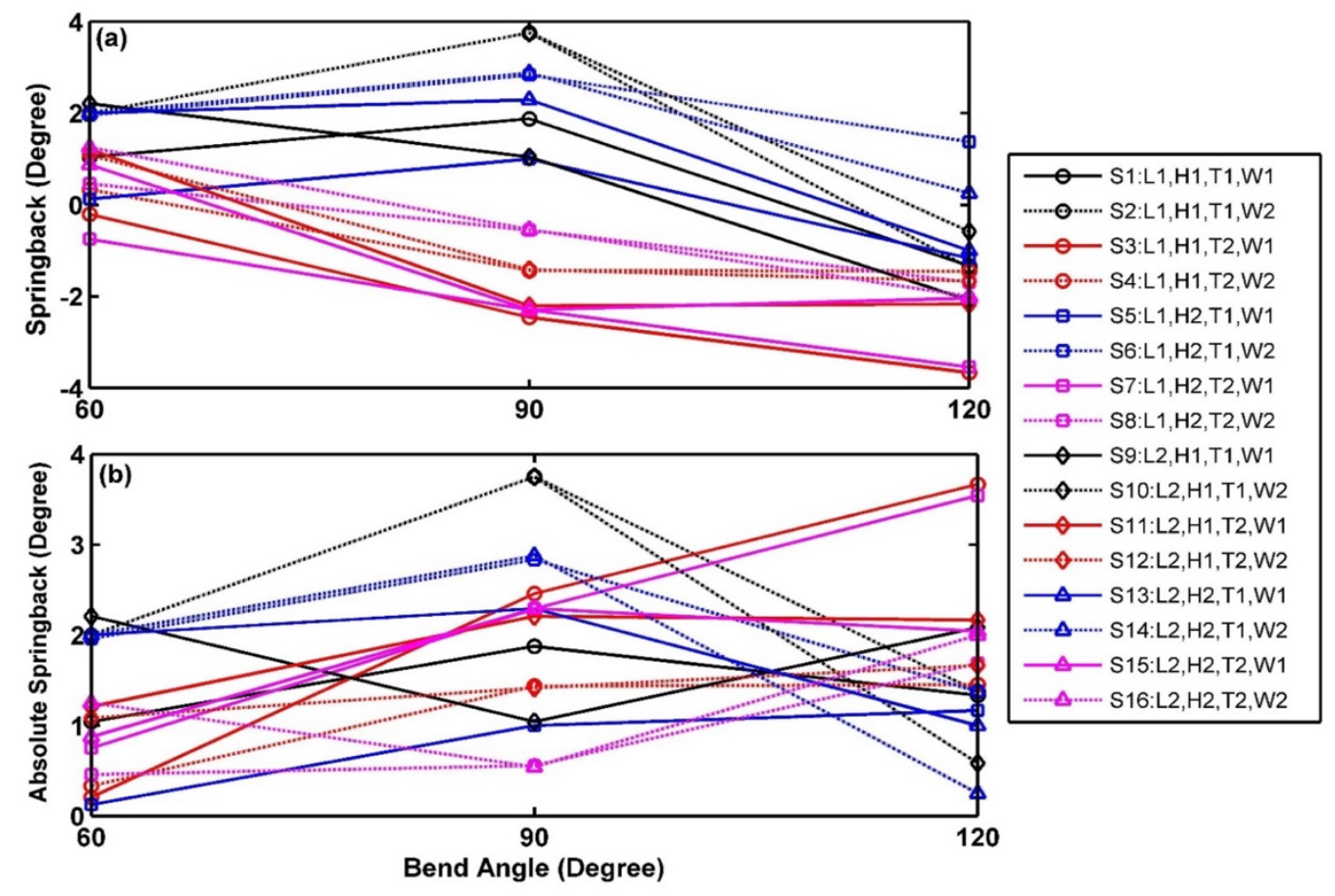

Figure 5. Variation in springback due to bent angles: (a) bent angle versus springback, (b) bent angle versus absolute springback.

From Fig. 5(b), the highest magnitude of springback is seen in the sheet metal blanks bent to $90^{\circ}$. It can be seen from the same figure that almost the same magnitude of springback occurs in the strips bent to $60^{\circ}$ and $120^{\circ}$, where slightly higher magnitude is observed in the strips having a thickness of $1.6 \mathrm{~mm}$ and width $20 \mathrm{~mm}$ and bent to $120^{\circ}$ (see Figures S3 and S7). In few cases, such as S3, S7, S11, and S15, the increase in bend angle causes the increase in springback magnitude (refer to Fig. 5(b)). 

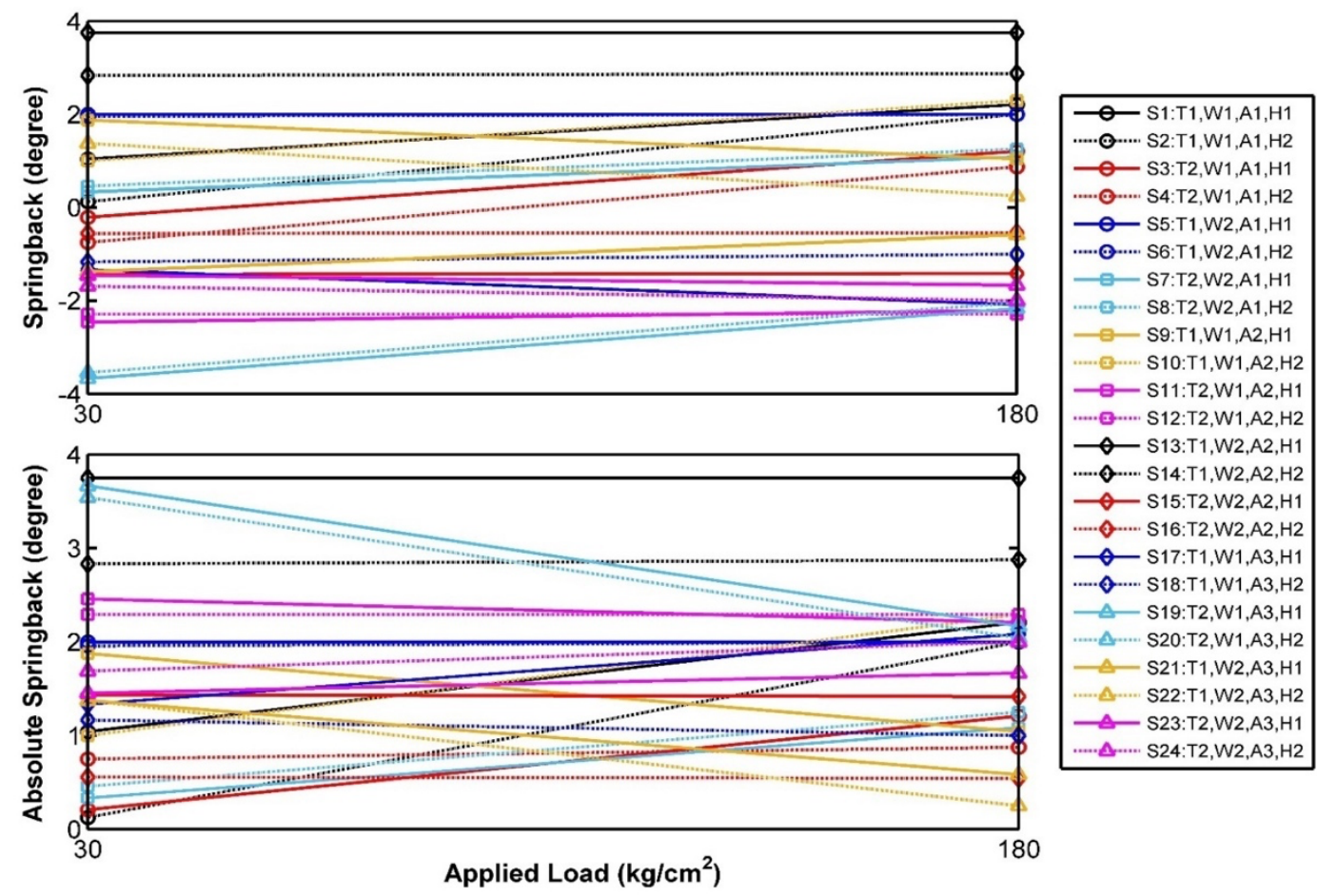

Figure 6. Variation in springback due to applied load: (a) applied load versus springback, (b) applied load versus absolute springback.

Fig. 6(a) shows the variation in springback behaviour with the change of applied load through the press. It shows that the highest positive springback is found over the strips bent to $90^{\circ}$ (curves S13 and S14), having the width of $50 \mathrm{~mm}$, which remains the same with the different applied loads. The highest negative springback is observed in the strips bent to $120^{\circ}$ with a minimum load of $30 \mathrm{kgcm}^{-2}$, having a thickness of $1.6 \mathrm{~mm}$ (curves S19 and S20 in Fig. 6(a)). From Fig. 6(b), changing applied load has mixed response over different types of strips. Springback increases with the increase in applied load only in the strips having a bend angle of $60^{\circ}$ and width of $20 \mathrm{~mm}$ (as seen in curves S1 to S4).

In most cases, springback does not change with the change in applied load, as seen in the curves S5 to S16, whereas, springback decreases as the applied load increases only in the strips bend to $120^{\circ}$, with varying widths and thicknesses shown in the curves S16 to S24. Hence, applying increased load does not affect the residual stresses stored in the JSH440 sheets bent to acute angles, whereas applied load releases the residual stresses during vbending of steel sheets if bent to obtuse angles minutely. Hence, based on ANOVA and Fig 6, it can be concluded that the varying load through the press does not significantly influence the springback.

In contrary to previous research, it can be seen from Fig. 7(a) that the effect of holding time on springback is relatively minor (Wasif et al., 2020). Negative springback in the strips bent to $120^{\circ}$ never changes with the holding time, as seen in the curves S17 to S25 of Fig. 7(a). An exception has been observed in curve S21, where the springback changed its behaviour from negative springback to positive one without change in magnitude. Hence, no change has been observed magnitude-wise in this curve in Fig. 7(b). Reduction in springback occurred with the increase in holding time in curves S1, S2, S13, and S14 (see Fig. 7(b)). It can also be observed that few exceptions are seen in curves S3, S7, S10, and S24 that the springback magnitude increased with the increasing holding time in JSH440, which is a pretty exceptional case. It may be due to the high-tensile strength and that the residual stress got 
strong during the holding time. Hence, based on Table 3 and Fig. 7, it can be said that holding time does not significantly affect the springback.

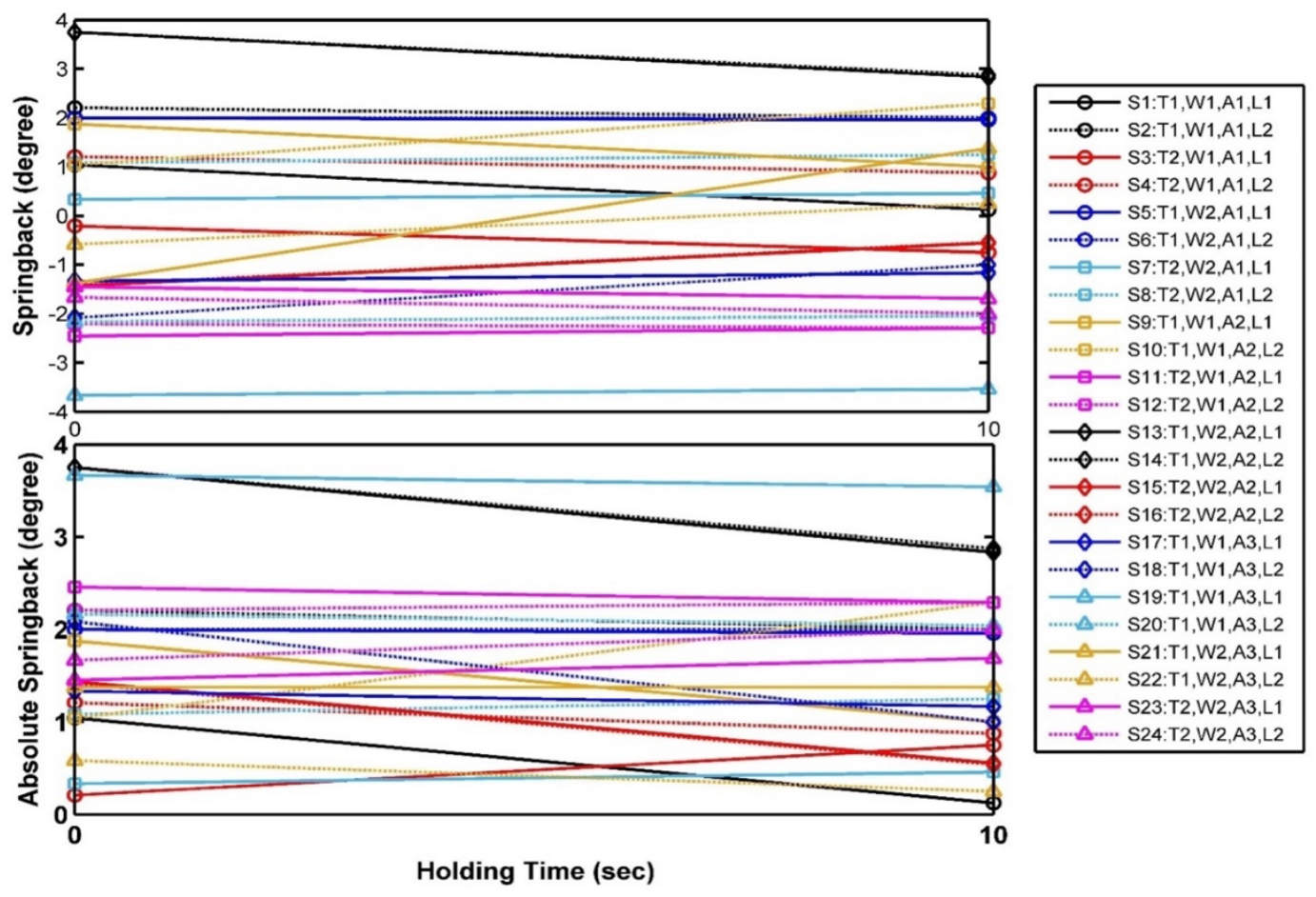

Figure 7. Variation in springback due to holding time: (a) holding time versus springback, (b) holding time versus absolute springback.

\section{ANALYTICAL MODEL AND OPTIMIZATION}

Analytical models of the springback in JSH440 sheet-metals are developed based on the measured springback in the metal strips. Eq. 1 presents the analytical model of springback for the JSH440 sheet metals, which relates the springback in the sheet metal with the controllable factors and their interactions. The model summary presents an R2 of $82.49 \%$, a good percentage of fit to the model.

$$
\begin{aligned}
\text { Springback }= & 9.7-7.9 T+0.077 W+0.115 A-0.0041 L-0.064 H-0.0006 A^{2}-0.0406 T \cdot W \\
& -0.0336 T \cdot A+0.013 T \cdot L-0.055 T \cdot H+0.0004 W \cdot A-0.0001 W \cdot L \\
& +0.0009 W \cdot H-0.0001 A \cdot L+0.0013 A \cdot H+0.0001 L \cdot H
\end{aligned}
$$

Let T, W, A, L, and $\mathrm{H}$ be the sheet-metal thickness, width, bend angle, the load applied, and holding time of load. Each coefficient of the equation represents the weightage of the influence over the springback. The coefficients less than or equal to $10^{-5}$ are omitted to have insignificant influence over the magnitude of the springback.

Since it is entirely practised in the industry to determine springback in the sheet-metals analytically for the bend angles, simplified analytical models based on the bend angles are also developed for different thicknesses and 
widths of the blanks, which are presented in Table 4. Quadratic equations are fitted on the experimental data of springback related to the bend angle (see Fig. 8). Equations of the curves $\mathrm{y}_{1}, \mathrm{y}_{2}, \mathrm{y}_{3}$, and $\mathrm{y}_{4}$ for the prescribed thickness and width of the blank are presented in Table 4.

Table 4. Quadratic Equations for the prediction of springback in JSH440 Sheets Metals.

\begin{tabular}{|c|c|c|c|}
\hline Blank Parameters & Curve & Equation & No. \\
\hline $\mathrm{t}=1.4 \mathrm{~mm}, \mathrm{w}=20 \mathrm{~mm}$, & $y_{1}$ & $=-0.0022 A^{2}+0.3646 A-12.75$ & $(2)$ \\
\hline $\mathrm{t}=1.4 \mathrm{~mm}, \mathrm{w}=50 \mathrm{~mm}$, & $y_{2}$ & $=-0.0038 A^{2}+0.6313 A-22.13$ & $(3)$ \\
\hline $\mathrm{t}=1.6 \mathrm{~mm}, \mathrm{w}=20 \mathrm{~mm}$, & $y_{3}$ & $=0.0005 A^{2}-0.1617 A+7.413$ & $(4)$ \\
\hline $\mathrm{t}=1.6 \mathrm{~mm}, \mathrm{w}=50 \mathrm{~mm}$, & $y_{4}$ & $=0.0009 A^{2}-0.2049 A+9.125$ & $(5)$ \\
\hline
\end{tabular}

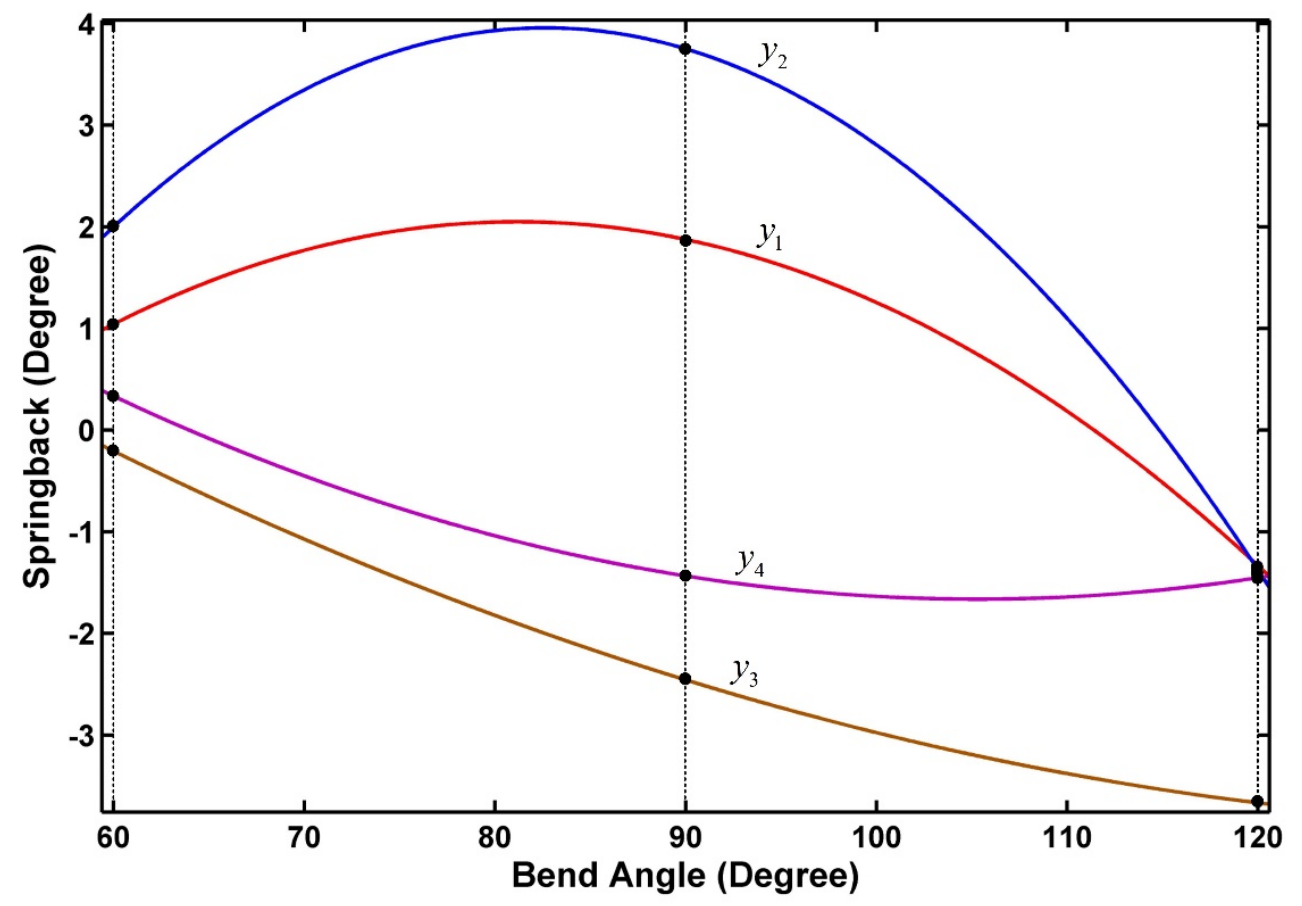

Figure 8. Fitted curves for the prediction of springback in JSH440 sheet metal.

Since the magnitude of springback is essential to the analysis here, hence absolute springback is minimized. Optimization has been applied for different types of blank geometry to obtain optimal machine tool process parameters for the minimum springback in the JSH440 sheet metals. The objective of the optimization is to determine the optimal process parameters for several blanks having different geometries. The following objective function represents the optimization problem: 
$z=\min |\operatorname{Spring} \operatorname{back}(T, W, A, L, H)|$

subjected to

$T=1.4,1.6$

$W=20,50$

$$
A=60,90,120
$$

$0 \leq L \leq 180$

$0 \leq H \leq 10$

A program has been written in MATLAB to apply the Genetic Algorithm (GA) over the optimization. The parameters of the optimizations are set as shown in Table 5 (MATLAB, 2020), whereas the optimal values of the process parameters for the minimum springback are shown in Table 6 .

Table 5. Parameters for Genetic Algorithm (GA).

\begin{tabular}{|c|c|}
\hline Parameter & Value \\
\hline Populations size & 200 \\
\hline Cross-over fraction & 0.7 \\
\hline Elite count & 10 \\
\hline Fitness scaling & Rank-wise \\
\hline Lower bound & {$[30,0]$} \\
\hline Upper bound & {$[180,10]$} \\
\hline Mutation and cross-over functions & Constraint dependent \\
\hline
\end{tabular}


Table 6. Optimal applied load and holding time for the minimum springback.

\begin{tabular}{|c|c|c|c|c|c|}
\hline $\begin{array}{c}\text { Thickness } \\
\text { (mm) }\end{array}$ & $\begin{array}{c}\text { Width } \\
(\mathrm{mm})\end{array}$ & $\begin{array}{c}\text { Bend Angle } \\
\text { (Degree) }\end{array}$ & $\begin{array}{c}\text { Applied } \\
\text { Load | } \\
\left(\mathrm{kgcm}^{-2}\right)\end{array}$ & $\begin{array}{c}\text { Holding } \\
\text { Time (sec) }\end{array}$ & $\begin{array}{c}\text { Minimum } \\
\text { Springback } \\
\text { (Degree) }\end{array}$ \\
\hline 1.4 & 20 & 30 & 30 & 10 & 0.245 \\
\hline 1.4 & 50 & 30 & 30 & 10 & 1.389 \\
\hline 1.4 & 20 & 45 & 30 & 10 & 0.859 \\
\hline 1.4 & 50 & 45 & 30 & 10 & 2.184 \\
\hline 1.4 & 20 & 60 & 30 & 10 & 1.203 \\
\hline 1.4 & 50 & 60 & 30 & 10 & 2.708 \\
\hline 1.6 & 20 & 30 & 127.661 & 4.033 & 0.000 \\
\hline 1.6 & 50 & 30 & 84.789 & 4.987 & 0.000 \\
\hline 1.6 & 20 & 45 & 132.67 & 8.915 & 0.000 \\
\hline 1.6 & 50 & 45 & 39.521 & 8.695 & 0.000 \\
\hline 1.6 & 20 & 60 & 114.489 & 6.537 & 0.000 \\
\hline 1.6 & 50 & 60 & 30 & 10 & 0.287 \\
\hline
\end{tabular}

Few optimal values of springback are still higher such as in the case of a $1.4 \mathrm{~mm}$ thick sheet, where the minimum springback attained is 2.184 or 2.708 . It is due to the springback regression model limitation, which cannot provide a lesser springback magnitude. Hence, the limitation of the springback model provided in the research is that it cannot optimize springback up to zero in JSH440 sheet metals for the thickness of $1.4 \mathrm{~mm}$. It successfully optimizes the springback up to zero magnitudes in most cases of thickness $1.6 \mathrm{~mm}$.

\section{CONCLUSION}

In contrast to the analytical and generic models of springback for the carbon steel sheets, JSH440 exhibits positive and negative springback. Based on the data gathered, analysis, and inference, the following results can be inference.

Springback in JSH440 sheet metals are significantly influenced by the geometrical parameters of the blank, which are thickness, bend angle, and width, in order of their significance.

- $\quad$ Springback versus thickness shows that springback directly relates to the thickness in the banks having the width of $20 \mathrm{~mm}$, whereas it decreases with the thickness in strips having higher width if bent to acute and right angles. A slight discrepancy to this behaviour is seen in the sheet metals bent to $120^{\circ}$. It occurred due to the bends' increased area, which stores more residual stress and causes higher springback. 
- Springback is usually directly proportional to the width, especially in the sheet metal bent to acute angles, whereas it shows a reverse behaviour in the strips bent to an obtuse angle. It can also be inferred from the analysis that the sheet metal bent to $90^{\circ}$ has a neutral effect in JSH440 sheet metals, where the behaviour of springback varies from negative to positive springback.

- Bent angle to springback relation shows that the highest springback is observed in the JSH440 sheet metals blanks when bent to $90^{\circ}$. The highest springback magnitude is positive. That is, the elastic recovery of the sheet metals increases the bend angle. In most of the sheet metals bent to $60^{\circ}$, positive springback has been observed, whereas, in the strips bent to $120^{\circ}$, negative springback is recorded generally. The highest magnitude of springback is seen in the JSH440 blanks having a width of 50mm.

- $\quad$ ANOVA results show that applied load has no significant influence over the springback in blanks of JSH440. However, a slight decrease in springback has been observed by increasing the applied load in the strips bent to $120^{\circ}$.

- Unlike the springback in other Carbons Steels, ANOVA and graphical analysis show an insignificant influence of the holding time over the springback.

- It can be seen from ANOVA that the interaction of controllable factors has little influence over the springback.

- $\quad$ Analytical models of springback in JSH440 have been presented. Eq. 1 presents an overall springback analytical model to determine the springback in JSH440 sheet metals. Specific quadratic equations for the prediction of springback in various geometries of JSH440 blanks are also presented.

- $\quad$ Finally, optimized machine tool parameters are presented for the minimum springback in the JSH440 sheet metals. A genetic algorithm has been used to optimize the process parameters. It shows the minimum springback in different blank geometries, which can be achieved through the optimal applied load and holding time.

Experimental investigation and analytical results state that hot-rolled, high-tensile strength sheet metals possess entirely different behaviours than traditional carbons steels. Negative and positive springback are present in these sheet metals during the v-bending process, which can be predicted using the analytical model presented in this article.

\section{ACKNOWLEDGMENT}

We present our immense regard to Mr. Ozair Mustafa, Mr. Fahad Qamar, Mr. Sohaib Ahmed Khan, Mr. Sadequain, and Mr. Arsalan Zaidi for providing their assistance during experiments.

\section{REFERENCES}

Balon, P., Rejman, E., Kietbasa, B., Smusz, R., Szostak, J.\& Cieslik, J. 2019. Comparison of springback value of the selected structure element for cold forming and hot forming methods, AIP Conference Proceedings, 2113(1): 100005, https://doi.org/10.1063/1.5112638.

Cai, Z.H., Batthyány, P., Dhawan, S., Zhang, Q.L., Sun, Y.H., Luan, X., Wang, L.L.\& Gharbi, M.M. 2019. Study of Springback for High Strength Aluminium Alloys Under Hot Stamping, Advanced High Strength Steel and Press Hardening 1: 117-121, https://doi.org/10.1142/9789813277984_0019.

Cardena, W.D., Genga, L.M., Matlockb, D.K.\& Wagoner, R.H. 2002. Measurement of Springback, Int. J. Mech. Sci. 44: 79-101. 
Choi, J., Lee, J., Bong, H.J., Lee, M.G.\& Barlat, F. 2018. Advanced constitutive modeling of advanced high strength steel sheets for springback prediction after double stage U-draw bending, Int. J. Solids. Struct. 151: 152-164, https://doi.org/10.1016/j.ijsolstr.2017.09.030.

Cui, X., Zhang, Z., Du, Z., Yu, H., Qui, D., Cheng, Y.\& Xiao, X. 2020. Inverse bending and springbackcontrol using magnetic pulse forming, J. Mat. Proc. Tech. 275: 116374, https://doi.org/10.1016/j.jmatprotec.2019.116374.

Da Silva, E.A., Fernandes, L.F., Silva, J.W., Ribeiro, R.B., Pereira, M.D.\&Alexis, J. 2016. A Comparison between an Advanced High-Strength Steel and a High-Strength Steel Due to the Springback Effect, IOSR Journal of Mechanical and Civil Engineering 13(5): 21-27, https://doi.org/10.9790/1684-1305012127.

Dong-juan, Z., Zhen-shan, C., Zhi-ying, C.\& Xue-yu, R. 2007. An analytical model for predicting sheet springback after V-bending, Journal of Zhejiang University SCIENCE A, 8(2): 237-244, https://doi.org/10.1631/jzus.2007.A0237.

Fei, D.\& Hodgson, P. 2007. Experimental and numerical studies of springback in air v-bending process for cold rolled TRIP steels, Nucl. Eng. Des., 236(18): 1847-1851, https://doi.org/10.1016/j.nucengdes.2006.01.016.

Inamdar, M.V., Date, P.P.\& Sabnis, S.V.2002. On the effects of geometric parameters on springback in sheets of five materials subjected to air vee bending, J. Mater. Process. Tech. 123(3): 459-463. https://doi.org/10.1007/s12206-013-0528-6.

JFE Steel Corporation, Hot Rolled Steel Sheets, JFE Steel Corporation, Japan. Available: https://www.jfesteel.co.jp/ (accessed on 14 June 2020).

Jung, J., Jun, S., Lee, H.S., Kim, B., Lee, M.G.\& Kim, J.H. 2017. Anisotropic Hardening Behaviour and Springback of Advanced High-Strength Steels, Metals, 7(11): 1-14, https://doi.org/10.3390/met7110480.

Kalpakjian, S.\&Schmid, S. 2013. Manufacturing Engineering and Technology (7th), Pearson Higher Education, USA.

Lang, K.,1994. Hand Book of Metal Forming (2nd), Society of Manufacturing Engineering, USA.

Leu, D.K.\& Zhuang, Z.W. 2016. Springback prediction of the vee bending process for high-strength steel sheets, J. Mech. Sci. Technol. 30(3): 1077-1084. https://doi.org/10.1007/s12206-016-0212-8.

Leu, D. 2019. Relationship between mechanical properties and geometric parameters to limitation condition of springback based on springback-radius concept in V-die bending process, Int. J. Adv. Manuf. Technol., 101: 913-926, https://doi.org/10.1007/s00170-018-2970-1.

Liu, C.G., Yue, T.\& Yu, X.T. 2019. Springback Analysis of the Stiffened Panel Milling from the Bent Plate. Int. J. Precis. Eng. Man. 20(2): 217-232, https://doi.org/10.1007/s12541-019-00031-1.

Liu, C., Yan, X.D., Yang, Y.\& Ye, W.2019. Research on the Springback of Square TA18 Titanium Alloy Tube on the Numerical Simulation, Mater. Sci. Forum. 944: 753-760, https://doi.org/10.4028/www.scientific.net/MSF.944.753.

Lin, J., Hou, Y., Min, J., Tang, H., Carsley, J.E.\& Stoughton, T.B. 2020. Effect of constitutive model on springback prediction of MP980 and AA6022-T4. Int. J. Mater. Form. 13: 1-13, https://doi.org/10.1007/s12289-018-01468-x.

MATLAB, Mathworks Inc. USA. Available on: https://www.mathworks.com/products/matlab.html (accessed on 14 June 2020).

Minitab, Minitab LLC. USA. Available: www.minitab.com (accessed on 14 June 2020). 
Nakagawa, Y., Mori, K.\& Maeno, T. 2018. Springback-free mechanism in hot stamping of ultra-high-strength steel parts and deformation behaviour and quenchability for thin sheet, Int. J. Adv, Manuf. Tech., 95(1-4): 456-467, https://doi.org/10.1007/s00170-017-1203-3.

Noma, N., Hashimoto, K., Maeda, T.\&Kuwabara, T. 2019. High accuracy springback simulation by using material model considering the SD effect, J. Phys. Conf. Ser. 1063: pp. 1-4. https://doi.org/10.1088/17426596/1063/1/012096.

Ozturk, F., Toros, S.\& Kilic, S. 2009. Tensile and Spring-Back Behavior of DP600 Advanced High Strength Steel at Warm Temperatures, J. Iron. Steel. Res. Int., 16(6): 41-46, https://doi.org/10.1016/S1006$706 \mathrm{X}(10) 60025-8$.

Pornputsiri, N.\& Kanlayasiri, K. 2019. Effect of bending temperatures on the microstructure and springback of a TRIP steel sheet, Defence Technology, available online, https://doi.org/10.1016/j.dt.2019.11.018.

Ramadass, R., Sambasivam, S.\& Thangavelu, K. 2018. Selection of optimal parameters in V-bending of TiGrade 2 sheet to minimize springback. J. Braz, Soc. Mech. Sci. 41: 21, https://doi.org/10.1007/s40430-0181521-x, 2018.

Ramezani, M., Ripin, Z.M.\& Ahmad, R. 2012. Modelling of kinetic friction in V-bending of ultra-highstrength steel sheets. Int. J. Adv. Manuf. Tech., 46(1): 101-110, https://doi.org/10.1007/s00170-008-1450-4.

Ren, H., Xie, J., Liao, S., Leem, D., Ehmann, K.\& Cao, J. 2019. In-situ springback compensation in incremental sheet forming, CIRP Annals - Manu. Tech. 68: 317-320, https://doi.org/10.1016/j.cirp.2019.04.042.

Slota, J.\& Jurcisin, M. 2012. Experimental and numerical prediction of springback in v-bending of anisotropic sheet metals for automotive industry, Zeszyty Naukowe Politechniki Rzeszowskiej. Mechanika 284: 55-67.

Tekinar, Z. 2004. An experimental study on the examination of springback of sheet metals with several thicknesses and properties in bending dies, J. Mater. Process. Tech., 145: 109-117. https://doi.org/10.1016/j.jmatprotec.2003.07.005.

Umur, Y., Aydin, H.\& Yigit, K. 2020. A. Bayran, Springback/Springforward Behaviour of DP Steels Used in the Automotive Industry, Tehnicki vjesnik, 27: 243-250, https://doi.org/10.17559/TV-20181004144024, 2020.

Wasif, M., Iqbal, S.A., Tufail, M.\& Karim, H. 2019. Experimental Analysis and Prediction of Springback in V-bending Process of High-Tensile Strength Steels, Trans. Indian Inst. Met. 73: 285-300, https://doi.org/10.1007/s12666-019-01843-5.

Yang, X., Choi, C., Sever, N.K.\& Altan, T. 2016. Prediction of springback in air-bending of Advanced High Strength steel (DP780) considering Young's modulus variation and with a piecewise hardening function, Int. J. Mech. Sci. 10: 266-272. https://doi.org/10.1016/j.ijmecsci.2015.11.028. 